\title{
The Role of IT in Automating the Business Processes in Retail Sector with Reference to Enterprise Resource Planning
}

\author{
Ramesh Babu Grandhi \\ Research Scholar, Department of Management, Suresh Gyan Vihar University, Rajasthan, India \\ *Correspondence: Ramesh Babu Grandhi, ramesh@sjcc.edu.in
}

\begin{abstract}
The information technology plays an important role as an enabler in retail industry to automate the business processes. The companies had identified that without the involvement of information technology the businesses cannot move forward with smooth running of business operations. With the advent of latest technologies in the field of information technology, companies are managing the business processes in more effective and efficient way. It is important to identify the importance of technological trends that had enabled the business processes to smoothen the operations such as technological enabler of the retail industry and its overall contribution to the sector as a whole. Enterprise Resource Planning, as the concept suggests, it can play a vital role in dealing with daily processes of the company. The importance of the Enterprise Resource Planning can deal with more challenging factors that a company faces and how well they can automate the processes is an advantage to the company at large.
\end{abstract}

Keywords: Enterprise Resource Planning (ERP), Retail, Information technology, Automation

\section{ARTICLE INFORMATION}

Author(s): Ramesh Babu Grandhi

Received: 09 Feb, 2021; Accepted: 16 May, 2021; Published: 15 June, 2021; e-ISSN: $2347-4696$;

Paper Id: BMN-IJBMR-2021-19;

Citation: doi.org/10.37391/IJBMR.090209

Webpage-link:

https://ijbmr.forexjournal.co.in/archive/volume-9/ijbmr-090209.html

\section{INTRODUCTION}

Information technology as an enabler plays a significant role in the overall contribution to the effectiveness of the company at large. Ecommerce had paid a significant role in the online business and there is a direct impact on the supply chain operations of the company at large. With the increasing globalization of retailing, both in terms of their points-of-sale and their points-of-supply; the information technology (IT) spend in the retail sector has increased significantly. IT plays an increasingly important role in the management of complex retail operations. Market knowledge, as well as control of data and information is key. Market knowledge and controlling the data is the key factor in scaling up the business operations. There must be a common system across the different platforms so that communication can be one of the key factors across departments in the company. The retail industry faces a series of challenges in terms of IT which can be an enabler in handling the customer data, transparency and tracking, and global data synchronization and security compliance also in terms of payments that would happen which is online in nature. The data is the key factor and how the data can be used effectively and efficiently is one of the important criteria for a company in terms of sales, operations, and scalability of the business at large. The impact of information technology has seen a tremendous surge in increase of sales in terms of food delivery apps that you see in the industry. The recent developments because of Covid-19 have left out no options for retail companies to force the technology into their daily business operations [1].

The customer engagement has been rated as one of the topmost priority of the business. Technology has changed the way where automation had paved the way for every aspect of the technology so that it can improve the service and can handle the operations on daily basis. Technology has changed at a rapid pace where $\mathrm{B} 2 \mathrm{~B}$ and $\mathrm{B} 2 \mathrm{C}$ types of conducting businesses. The daily business operations are spreading at a rapid pace and the scalability i.e. the volume of the business in gaining more vendors in terms of business expansion [2].

The retailers must understand the concept of big data and how it can be leveraged in terms of expanding its business operations at every stage. How exactly the customer data is a significant step in gathering and making the most use of the same? The latest technologies like IOT-Internet of things, where the data storage happens at different data centers across the globe and make sure that cloud-based environment is a no option for different clients across the globe. The retailers can benefit to the maximum with the big data where the customer details are updated and validated from time to time. The personalized recommendations given by customers' postpurchase are significant steps for the customers to leverage upon. The walk-ins across the store would increase and the contact details of the prospect need to be maintained by proper follow-up and thereby leading to the sale [3].

The increase in retail spending across the companies had a huge surge impact on the usage of technology at large. The technologies evolved in retailing and use of smart tag technology such as RFID, Radio frequency of identification does play a role in the identification of features regarding the product, i.e. right from the billing stage to the delivery of the product to the customer place. POS-Point of sale is an important technology for the retailer, where the transaction 
codes are recorded with the minimum infrastructural space. Usage of advanced CRM and Enterprise Resource Planning software would enable the retailer to take at most leverage of the technology at large. Integration of all the departmental data and how effective the maintenance of the data is taken care of by using the advanced automatic processes is one of the key factors about the effectiveness in the use of the data [4].

Information systems play a vital role in setting up of retail operations. Inventory Management System plays an important role in the overall check and it maintains the data in the systems at large in the form of Asset Tracking. An accounting information system checks the data in the form of collecting, storage, processing the data and helps the management in the decision making. The customer data is also extracted and can be used for communication in many aspects in terms of the promotion of the products. There is an effective CRM system that needs to be in place to communicate effectively and efficiently. The MIS brings out overall systems together and gathering of specific information and displaying them in the form of dashboard gives extra ease to the top management to take a decision [5]

\subsection{Three Successful Enterprise Resource Planning Implementations}

It is the process of implementation of the software across the departments in the organization. Installing the software with a SaaS provider gives an edge to the organization. There are three stages of Enterprise Resource Planning Implementation i.e. Installing, Migrating, and Training. The successful Enterprise Resource Planning implementation can facilitates the company in overall growth and prospects of the company at large. An Enterprise Resource Planning implementation is a process: of vendors and reviewers alike recommend carefully evaluating vendors and/or partners before beginning, as well as taking things one step at a time, setting expectations with realistic planning timeframes and a comprehensive checklist mapped to your company's goals for the system. To centralize all work in one place, the company's co-founders implemented Net Suite After a three-week implementation process, changes were immediate, according to team members. Finally, the Fulton \& Roark team was able to stop working with external accountants, growing both unit and dollar volumes significantly with no extra headcount.

The improvements are expected after retail Enterprise Resource Planning is used in merchandise management, more efficient and fulfillment control and more accurate customer databases. The effectiveness of the databases can be utilized for the promotion of their services. The categories of the different products across the spectrum can be identified with ease. The coordination across different merchandises across the spectrum is the important factor of the company in scaling up of the operations on a larger scale. In the retail store, the fulfillment control is said to be as displaying the products at the optimal location. The software can track various information related to the businesses and scope of it at large [6].
The factors influencing Enterprise Resource Planning implementation in the retail sector are follows:

- Increase sales roughly 50\% year-over-year without increasing headcount.

- Get a more accurate picture of margins and inventory, which helped in growing of its ecommerce operation. Enterprise Resource Planning implementation is very much useful and can be integrated well across different departments in the company.

- The investigation says that there are various factors that can influence the relationship between Enterprise Resource Planning implementation at large. The factors such as strategic, technological and the people. Project management factors are of great influence in terms of implementation of Enterprise Resource Planning Package in the organization [7].

\subsection{Objectives}

- To evaluate the effectiveness in usage of technology in the business processes.

- Significance of customer data in business for decision making.

- GAP analysis of the infrastructure in scaling up of business.

The technology can be more effective in the usage of the business processes to increase sales and make the supply chain more efficient way. The data collection mechanisms can have a significant impact in dealing with the overall approach in taking an appropriate decision at the right time. The predictions in terms of customer behavior are the key for the marketer and can strategize the needs of the customer accordingly. The marketer can easily predict the needs of the customer and strategize the business operations most effectively. The technology can be an important need for the business whereas the overall products that are sold on a daily basis need a track on the inventory mechanism. With the help of the software, the tracking mechanism can take place and appropriate decisions can be made at the right time. One of the important aspects of automating the business processes is the workflow software, the approvals across the different levels of hierarchy is automated with the help of workflow design and the decision-making would rest on the hierarchies within an organization. The daily performance control can be tracked with effectiveness in the usage of the software at large.

The POS-Point of sale system can allow the company to interact more with the customer in understanding his purchasing patterns and the transactions can take at a faster pace. Improving the customer experience allows you to accurately and easily check for the details. It can also allow you to easily check for the details and have stock levels at a glance. Augmented reality is the important technology trend that's happening at the retail store. The user cameras are installed at the specific locations at the store and that would make the customer experience more fulfilling in terms of purchase. There are different technological patterns where the significance of the data can be taken as leverage and they can 
capitalize on the overall foundations of the data by taking an appropriate decision at the right time (Figure 1) [8].

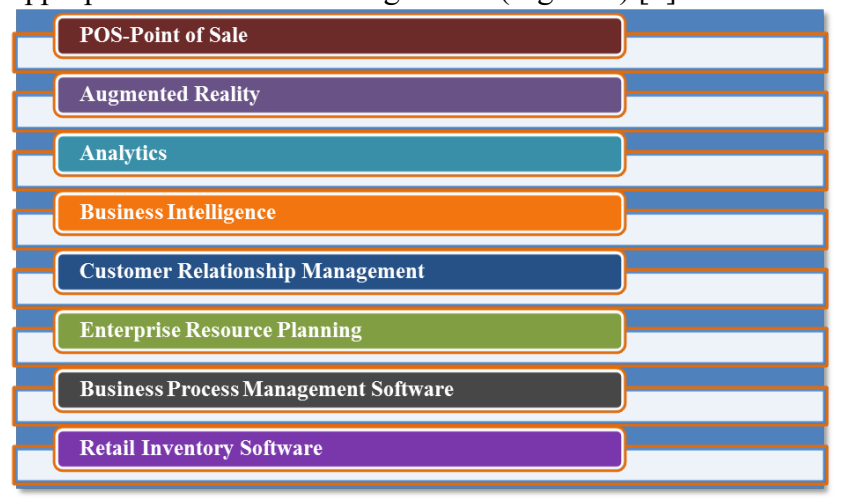

Figure 1: The technology trends in the retail industry.

The various technologies can lead to a significant impact on the overall systems and processes of the retail company at large. How effectively the companies can use these technologies can be used is a big challenge for the companies. The smart usage of these technologies can pave the way for the smoother functioning of the companies.

\section{LITERATURE REVIEW \\ 2.1 Enterprise Resource} Implementation in Pantaloon Retail

Planning

Pantaloon Retail is the flagship company of future group that caters to the needs of the consumers in India at large. The company had huge walk-in on daily basis and paved the way for 30,000 small entrepreneurs in the world. Currently the company serves 1000 stores across 71 cities in India.

\subsubsection{Need for an automation solution}

The company is looking for information technology automation software to set up its store operations and integrate all the units at large and solve the issues such as tracking of financial information, deft handling of complexities, expediting the reconciliation process. After a comprehensive evaluation of different options and software companies, the management at Pantaloon decided to go in for SAP's retail solution. This was because SAP had a solution specifically directed at the retail sector, which met much of Pantaloons' requirements. SAP being the market leader in the Enterprise Resource Planning vendor space, it was believed that SAP was the best possible solution provider. The company was able to implement this software after approval from the top management [9].

\subsection{Stages of Enterprise Resource Planning Implementation in Retail Industry \\ 2.2.1 Planning phase}

The organization would do the Research on various available products in the industry for the implementation; the internal stakeholders of the company are reviewed in the process. The overall stakeholders in the project are selected and finalized for the implementation process. Whatever the challenges and perspectives are to be faced, they had to be done in the phase for the decision-making process.

\subsubsection{Design phase}

The complete workflow systems across the departments are visualized and the departmental heads must be involved in the process to understand the specific requirements. The experts are bought into the phase so that overall systems are aligned when the implementation of the software to be analyzed. Detailed analysis is made with the overall features of the product and how effectively it can be a right fit to be analyzed in this phase.

\subsubsection{Development phase}

The configuration of the systems and how effectively the current application can contribute, which can lead to the implementation of the product is the key factor. The training manuals that are related to technologies should be drafted and information sharing would be done by the respective teams. The specifications regarding various software and the advantages of it can be clearly mentioned in this phase. The coding and the programming languages that can be used at this stage dealt with and the right programming language used during this stage can be taken a decision.

\subsubsection{Testing}

This stage involves the migrated data and the end-user analysis. The testing of the application can be done by Automation tools like win runner, load runner, silk test. These tests would give accurate results that can emphasize the quality of the product which is about to get deployed in the market. Even there is a test that is done with the automated form. Manual testing is a must for any product. At all the stages when the product is getting tested, it has to be documented by recording a specific set of information relating to the testing process and the functioning of the product.

\subsubsection{Deployment and support}

The final stage of the software development process is the deployment of the project at the client's place with the onsite team. The Installation of the Enterprise Resource Planning can be taken in a serialized manner or at once, based on the need of the client. The support in case of post-implementation of Enterprise Resource Planning is useful for the client based on the Annual Maintenance Contract between the client and the company [10].

\section{RESEARCH METHODOLOGY}

The first step is to identify the technological tools of the retailer and finding out the detailed analysis in terms of system requirements such as the network capabilities and the software tools in usage, whether the technology is been used by the company at large. Finding out the training gaps also is an important aspect; the objective of the company is to make sure the resources are equipped with sufficient knowledge of the tools in the organization. The GAP analysis can be done by the company in terms of infrastructural requirements, by setting the benchmark at large. The analysis and integration are to be done to find out the possibility of the company scaling up in 
terms of infrastructure. The analysis of the data and time taken to implement the software needs a detailed study and must get approval from top management at every stage of the implementation. The conclusion is the signoff document between the client and the company who is a technology partner, once he is satisfied with the services provided by the implanters (Figure 2).
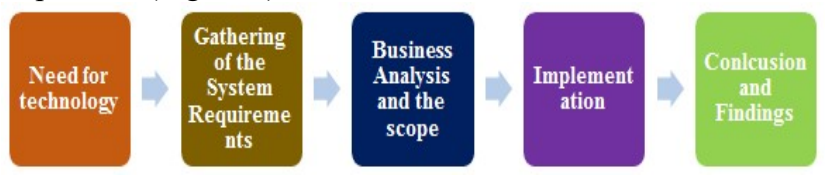

Figure 2: Research flow.

There is a survey that is conducted where the use of automation tools in the form of AI had delivered very good results and it has helped the companies to build the business processes at large. This has paved the way for the companies in experimenting with new products and the approach of the top management is very much positive. The statistics of the same are mentioned below (Figure 3) [11].

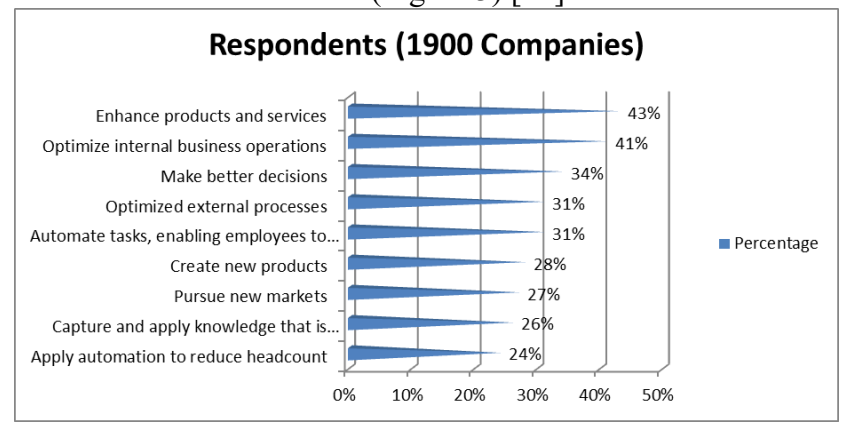

Figure 3: Survey statistics.

\section{CONCLUSION AND FINDINGS}

By the research, we can suggest to the company who is in retail that there has to be a more effective way in dealing with business by using proper automotive techniques. The trends can give potential to the startup company and can take leverage on the existing infrastructure at large. We can say that with the proper use of the technologies we can change the customer perspective towards purchasing a product or a service at large. Enterprise Resource Planning software can have a significant impact on the overall prospects of the company when dealing in business.
The overall time taken for the implementation differs from the company to company based on the scale of the operations of what is in to, the functional consultants can be brought into the initial stage and the later the technology consultants can take over the needs and specifications as said by the company.

\section{REFERENCES}

[1] CBN. (2020). The state of retail tech. Arizona: CB Insights.

[2] Pangriya, R. (2020). Automation in Retail: Modern Ways of Customer Engagement. PalArch's Journal of Archaeology of Egypt/ Egyptology, 17(7), 10507-10533.

[3] Shankar, V. (2020). Big Data and Analytics in Retailing.

[4] Shet, A. R. (2015). Information Technology in Retail Sector. International Journal of Scientific Engineering and Research (IJSER), 3.

[5] Lumen learning. (2018). Retail Management.

[6] Miller, T. (2018). Three improvements to expect after retail ERP implementation.

[7] Atul Garg, P. G. (2014). Factors influencing ERP implementation in retail sector: an empirical study from India. Journal of Enterprise Information Management, 27(4), 424-448.

[8] Melo, S. (2018). How to use technology in the retail industry?

[9] Girsih, N. G. (2013). ERP System Implementation at Pantaloon Retail. SDMRCMS.

[10] Schwarz, L. (2020). 6 Key Phases of an ERP Implementation Plan.

[11] Lisa Schwarz . (2020). Netsuite.

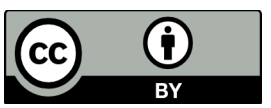

(C) 2021 by the Ramesh Babu Grandhi. Submitted for possible open access publication under the terms and conditions of the Creative Commons Attribution (CC BY) license (http://creativecommons.org/licenses/by/4.0/). 